\title{
La aventura como categoría cultural: apuntes simmelianos sobre la emigración subsahariana*
}

Este artigo é uma reflexão teórica sobre a imigração africana, tendo como referência os diálogos com os amigos na África e Europa. Uma vez que o fenômeno migratório se assemelha a uma aventura, pois envolve alguns riscos para as pessoas, eu proponho que a migração seja considerada uma categoria central nesse processo de deslocamento.

Palavras-chave: África e Europa - Antropologia - Migração - Aventura - Georg Simmel.

\author{
Ramon Sarró ${ }^{1}$ \\ Universidade de Lisboa
}

This article is a theoretical reflection on African immigration, taking as investigative support the dialogues with friend in Africa and Europe. Migration is like an adventure, since it involves initiative and risks to people, and the relation between anthropology and adventure is examined in accordance with the Simmelian model.

Keywords: African and Europe - Anthropology-Migration-Adventure-Georg Simmel.
No hay lugar para la aventura en la profesión del etnógrafo. LÉVI-SRAUSS (1945; p. 1)

Adventure and anthropology are coupled like Siamese twins. YENGOVAN (2006; p. 27)

\section{Simmel en Lisboa}

$\mathrm{H}^{2}$ ace casi cuatro años conocí en Lisboa al que ahora es mi buen amigo Kimi Djabaté, un músico mandinga originario de Guinea Bissau, cuya banda musical de entonces, con la que grabó su primer CD, se llamaba "Tamala".

\footnotetext{
"The adventure as a cultural category: simmelian notes on SubSaharian immigration

${ }^{1}$ Quería agradecer los comentarios y sugerencias de algunas de las muchas personas con quien, en ciertos momentos, en seminarios y en cafés, discutí ideas presentadas en este trabajo: Marina P. Temudo, Kimi Djabaté, Aboubacar Camara, Amir Geiger, Ronaldo Castro, Josep M. Casasús, Clara Mafra, Bela Feldman-Bianco, José Mapril, Lorenzo Bordonaro, Alicia Campos, Itzia Ruiz-Jimenez, Alvaro M. Maluquer y Ruy Llera Blanes. En especial quería agradecer a Bela Feldam-Bianco y a Cristiana Bastos por haberme convidado a participar en el proyecto Circulação Transnacional, Fronteiras e Identidades (financiado por CAPES-GRICES), en cuyo ámbito desenvolví muchas de estas reflexiones, discutidas en forums del mismo en Lisboa, y gracias al cual pude además desplazrme a Brasil en Septiembre de 2006, donde las discutí con varios de los colegas citados, sobre todo en un seminário de antropologia en la Universidade Estadual de Rio de Janeiro. Endereço para correspondências: Instituto de Ciências Sociais da Universidade de Lisboa, Avenida Professor Aníbal de Bettencourt, 9, Lisboa, Portugual, 1600-189 (ramon.sarro@ics.ul.pt)
} 
Cuando le pregunté por qué se llamaba así me respondió que en mandinga tamala significa "los aventureros", concepto que glosó como aquéllos, entre los que se contaba, a quienes les gusta viajar y conocer mundo.

En este artículo propongo algunas claves para repensar la emigración africana desde una óptica a la vez analítica y subjetiva. Se trata de una exploración teórica más que una investigación empírica. Propongo hacerlo desde la centralidad de "aventura" por tres razones. En primer lugar, porque "aventura" es, como se acaba de ver, un concepto utilizado por los propios africanos para describir su experiencia migratoria. En segundo lugar, porque es un ángulo que convida a ver la migración desde la óptica de la acción, la iniciativa y el riesgo, y no desde el victimismo, el trauma o la desesperación economicista. En tercer lugar porque la aventura permite establecer un vínculo entre la experiencia de la emigración y un texto de referencia obligada en el pensamiento social contemporáneo: el conocido artículo de Simmel "la aventura", publicado por primera vez en 1911 (SIMMEL, 1911a). Como el lector ha visto, he abierto el texto con dos frases contradictorias. No espere que voy a solucionar la ambigüedad generada por ellas (como veremos, la ambigüedad acompaña a menudo a la aventura). Precisamente las he escogido para obligar a quien me lea a hacerlo desde la perplejidad. El presente artículo, en efecto, quiere ser thought provoking. Más que ofrecer respuestas, pretende incitar preguntas. Y en cualquier caso, las preguntas que yo me hice en su raíz no tenían a ver con la relación entre la aventura y la antropología (éstas las dejo para quien me esté leyendo) sino con la relación entre lo que me cuentan mis amigos africanos en África y en Europa y lo que nos contaba Simmel en su artículo seminal.

Georg Simmel es sin duda uno de los pioneros del pensamiento social y filosófico sobre la condición humana de la polis moderna. Ávido por explorar todos los rincones de la subjetividad, Simmel se entregó con su inusual intuición y penetración a elucidar los significados de aquel tipo de experiencias que, de una forma intuitiva, todos denominaríamos "aventuras": desde el viaje a un país lejano hasta un breve lance amoroso (el lance amoroso, en virtud de su relación intrínseca entre riesgo, suerte e intensidad de lo vivido es para Simmel un perfecto ejemplo de aventura, pero no por supuesto el único). En este texto, de una gran profundidad filosófica, Simmel argumenta que la aventura es un momento en la vida de un individuo que es dotado de una cierta "extratemporalidad" y "extraterritorialidad". La aventura nos acontece y pertenece; nosotros somos los protagonistas; sin embargo, el espacio y el tiempo de la aventura quedan tan bien acotados que a menudo la recordamos luego como habiendo sido protagonizada por otro. La aventura, como dice Simmel, es parecida con el sueño. Lo es, por lo menos, en dos sentidos. En primer lugar por su carácter claramente externo a la continuidad de nuestra vida habitual y rutinaria, por tratarse como de un pedazo extraído de la vida, con su inicio y su fin claramente delimitados. 
En este sentido, no dirá Simmel, la aventura, por ser un todo tan bien acotado, se parece también a la obra de arte. En segundo lugar, la aventura se parece con el sueño porque en éste el protagonista actúa sin pensar mucho en su acción, como si ésta fuera independiente del marco en el que acontece. El soñador avanza y aunque el sueño - como la vida misma - esté lleno de accidentes y de azar, el soñador siempre sigue adelante sin que estos elementos le frenen. Así también el aventurero, según Simmel, vive su aventura con una "seguridad sonámbula", más preocupado por sentir la plenitud de sentido que le está ofreciendo la aventura que en pensar que algún accidente o mala suerte pueda ponerla en riesgo o incluso terminar con ella. Como el jugador, el aventurero se lanza a la suerte, confiando no sólo en su hado, sino también en la fuerza y determinación de que se siente dotado. "Siempre en la carretera, siempre adelante" como me decía hace apenas unas horas Vicente, un angoleño que vive en mi barrio de Lisboa que, según me cuenta, acaba de volver de trabajar en España y se prepara, con el entusiasmo propio de los aventureros, para irse a trabajar a Noruega.

Recientemente, un alud de antropólogos, al que aquí me sumo, se han aventurado a explorar las ideas de Simmel y su relevancia para nuestra disciplina pese a las dilapidarias palabras de Lévi-Strauss citadas al inicio de este texto. Así, Huon Wardle (1999) ha utilizado el concepto de aventura para penetrar en la imaginación de jóvenes jamaicanos; Lorenzo Bordonaro nos ha mostrado que la aventura es una buena herramienta para pensar las fantasías migratorias de los jóvenes bijagós de Guinea Bissau (BORDONARO, 2006; Bordonaro está sin embargo más influenciado por la "sociología de la aventura" de MAFFESOLI [1997] que por el texto simmeliano). El libro de Vivanco y Gordon (2006) recoge una buena serie de artículos que aplican la noción de aventura a diversas situaciones aventureras, de una forma, hay que decirlo, bastante circular y tautológica: los artículos parten de Simmel y de su definición de aventura para demostrar que existen en el mundo diversas situaciones (desde Tarzán hasta el malogrado "buscador de cocodrilos" australiano Steve Irving, pasando por los alpinistas y los peace-corps) que demuestran que Simmel estaba cierto, pero uno se pregunta si era preciso ilustrar algo tan sencillo como que existen las aventuras y como que Simmel es el mejor teórico sobre ellas, sin acrecentar nada en las reflexiones filosóficas de éste.

Todos estos autores nos muestran con convicción que la aventura es una buena herramienta analítica para hablar sobre (subrayo el "sobre") experiencias de individuos humanos, que van desde los jamaicanos o los bijagós a los turistas y voluntarios de la cooperación internacional. En mi caso, en vez de utilizar el concepto sólo como herramienta analítica (aunque también sea eso), lo que me propongo es también utilizarlo para hablar con individuos que, de una forma u otra, han dado en tildar ciertas experiencias de "aventura". 
Lo que me interesa no es sólo (aunque también) demostrar que las ideas del genial pensador alemán puedan aplicarse a la comprensión de seres humanos, sino documentar que el concepto de "aventura" es también usado por una gran diversidad de personas (y, en particular, por los africanos) y que por lo tanto no es sólo un instrumento, sino también un punto de encuentro, una plataforma de genuina comprensión humana.

A pesar de que la lectura superficial de Simmel (como es, según mi criterio, la de los autores citados), parece quedarse en describir lo que es una aventura y cuáles son sus elementos esenciales (extraterritorialidad, falta de ligación entre lo vivido en la aventura con el pasado y con el futuro del aventurero, combinación de acción calculada y suerte impredecible, etc.) el texto del pensador alemán tiene de hecho una intención mucho más profunda y, en cierta forma, hasta educativa. Para Simmel, la aventura no es sólo una actividad que acontece en los extramuros de nuestra vida cotidiana. Es mucho más que eso: es una "forma de vida" (Lebensform) o una "forma de experiencia" (Form des Erlebens) en la que la plenitud de la vida es sentida de forma privilegiadamente aguda, por ser un microcosmos en el cual la acción individual se impone, de forma consciente, sobre los determinantes y los obstáculos que se imponen a nuestra vida, como de forma inconsciente y rutinaria acontece en nuestra existencia toda. La "aventura", en este sentido, es una categoría que permite pensar aspectos de la vida humana tan solemne como el "arte", la "religión" o la "moral". Simmel parece decirnos que en la aventura se resume la vida entera, y que somos todos "aventureros en tierra" (SIMMEL, 1911a; p. 137). De hecho, hasta parece querer decir que lo más sabio seria aprender a vivir no pequeñas aventuras a lo largo de la vida, sino la vida toda como una gran aventura. En este sentido, también, su texto se aplica particularmente bien a los emigrantes africanos, quienes a menudo describen el trayecto migratorio como un proceso de aprendizaje sin retorno. La migración no es un "viaje" del que uno puede retornar, sino un cambio total y radical en el que el individuo aprende a vivir la vida con un sentido pleno otorgado por su propio movimiento. "En la carretera siempre, siempre adelante".

Conviene insistir que, contrariamente a lo que algunos críticos de mi texto podrán pensar, no estoy oponiendo aventura a "necesidad", y mucho menos a sufrimiento. Decir que los africanos vienen a Europa "por aventura" no equivale a decir que vengan "de vacaciones". Tampoco equivale a decir que en Africa hoy no haya necesidad de emigrar: no quede duda de que la hay. Tampoco quede duda, sin embargo, de que no todos los emigrantes viajan por estricta necesidad y que tanto derecho tienen de viajar y de mudarse de país unos como otros. Soy consciente de que mi discurso puede tener este efecto perverso: el de hacer pensar que la gente emigra por ansia de aventura y el de legitimar que se obvien así muchos sufrimientos, e incluso que se justifiquen los cierres de fronteras. 
"Puesto que sólo vienen por aventura, entonces tampoco será tan necesario dejarlos venir", rezaría el argumento conservador inspirado por mi texto. Desde mi punto de vista, como desde el de Simmel, sin embargo, la aventura y la necesidad no están reñidas (para Simmel, sólo hay aventura en la medida en que estamos venciendo algún obstáculo). Son fenómenos que deben ser tratados de forma independiente, yo mismo he tratado otros aspectos de la emigración en otros textos (sobre el sufrimiento, en particular, véase SARRÓ, 2006). Pero tienen innúmeros puntos de contacto. De hecho, hay que ser un gran aventurero para poder afrontar el enorme sufrimiento a que somete el traslado migratorio. Decir que los africanos vienen a Europa por aventura no es minimizar, ni ridiculizar, ni relativizar su viaje. Es sólo respetar su forma de hablar y entregarles un derecho del que Europa, en su momento, también se hizo dueña y señora: el de conocer, en persona y no sólo en relato, aquellas tierras sobre las cuales tanto se nos ha hablado. Como me señaló en cierta ocasión mi colega Itziar Ruiz-Jiménez, en unos comentarios a una versión oral y preliminar de este trabajo, el carácter aventurero se complementa con los factores estructurantes de la emigración. Probablemente, argumentaba Itziar, cuando en el seno de una familia africana se discute cuál es el miembro que va a emigrar para Europa, lo más probable es que el talante de cada uno sea tenido en cuenta, y que se escoja a aquellos que sean, por naturaleza, más aventureros que otros.

Lo que sí creo, de cualquier manera, es que nuestra insistencia en hablar de sufrimiento, de necesidad y de problemas económicos tiene también su efecto perverso: el de no aceptar que hay gente cuyo viaje no se ajusta a este modelo y autorizarnos por lo tanto a no aceptar su presencia entre nosotros. Los emigrantes africanos, en su proceso de aprendizaje migratorio, aprenden que el lenguaje de los europeos excluye la aventura. Así me lo explicó un día Kimi. Cuando le dije que quería escribir un artículo sobre la aventura, así, sin más, me confesó estar positivamente sorprendido. "No imaginaba a un blanco querer escribir sobre esto" dijo; "es más propio de africanos pensar así". Según él, los blancos no creen que a los africanos también les guste conocer mundo. Incluso, en ocasiones, ellos propios tienen que esconder su afán aventurero. Así, me contó de un joven amigo que fue al SEF (Serviço de Estrangeiros y Fronteiras) para solicitar un permiso de residencia en Portugal. El muchacho escribió una solicitud en el que argumentaba que le gustaba mucho vivir en Portugal, que era un país que tenía ganas de conocer mejor y que los portugueses lo estaban tratando muy bien. Le denegaron el permiso. Cuando mostró el texto a una persona más experimentada que él, ésta le dijo que con ese texto estaba claro que no iría muy lejos y le recomendó empezar de nuevo. El joven escribió una segunda solicitud en la que decía que había salido de su país por presiones políticas y económicas. Que en su país había muchas guerras, hambre y miseria. 


\section{HüMANAS}

Que su único objetivo en la vida era trabajar para recoger dinero y poder mandarlo a su familia en su pais de origen y así ayudarlos y ayudar de paso a su pais. Al cabo de pocos días, tras aprender de sus mayores, como hacemos todos en la vida, el joven volvió al SEF, entrego su solicitud, que fue positivamente valorada, y posee hoy su permiso de residencia...

No tengo ninguna información sobre cuándo los africanos empezaron a hablar de "aventura", pero sin duda desde, por lo menos, la primera mitad del siglo XX. La referencia clásica más obvia es la novela del escritor senegalés Cheikh Hamidou Kane que lleva el sugerente título de L'aventure ambiguë (1961) en la que el autor narra su formación escolar (coránica y, luego, francesa). Pero unos años antes de la aparición de esta novela, en otra obra francófona igualmente famosa e igualmente autobiográfica, L'enfant noir, de Camara Laye (1923-1968), el autor, un escritor de la entonces colonia de Guinea nos hablaba de sus tíos maternos con unas sugerentes reflexiones sobre la aventura. Uno de los tíos aparece a menudo en la novela y mantiene con el pequeño Laye una de aquellas relaciones jocosas tan propias de la relación avuncular y tan conocidas en la antropología social. Su hermano gemelo, sin embargo, siempre está ausente. Camara Laye nos explica que, prácticamente, no lo conoció más que una vez:

[Mi tío] sentía poca inclinación por la tierra; iba siempre de un lado a otro; (...) llevaba el gusto de la aventura en la sangre. Sólo lo vi una vez; había venido a Tindican. Hacía unos días que había llegado y ya sólo soñaba en irse de nuevo. He conservado el recuerdo de un hombre extremadamente cautivador que hablaba mucho, que no paraba de hablar y que no se cansaba de escuchar. Explicaba sus aventuras, que eran extrañas, que te transportaban que te abrían horizontes sorprendentes. Me llenó de regalos (...) ¿Cómo se llamaba? Ya ni me acuerdo; tal vez no lo supe nunca (LAYE, 1953; p. 38).

Este fragmento es significativo porque, en primer lugar, demuestra como el concepto de aventura era invocado y la experiencia aventurera percibida en el Africa rural de los años 30 o 40, cuando Camara Laye era un niño. En segundo lugar, porque muchos de los elementos que se nos describe son claramente simmelianos: la relación entre la aventura y el sueño; el carácter cautivador del aventurero; la ausencia de nombre (y por lo tanto de pasado) del aventurero, etc. Es perceptible, también, el efecto epidemiológico del relato aventurero: nuestro joven protagonista se dejará seducir, por no decir contagiar, 
por las aventuras de su tío materno. También él, como sabremos al final del libro, se convertirá, para desesperación de su madre, en un aventurero. Se irá a estudiar a Conakry y luego, con una beca del gobierno colonial, a Paris, donde se convertirá en uno de los escritores más justamente conocidos del movimiento de la negritud.

Una posible hipótesis sobre los orígenes del uso del concepto en Africa apuntaría a que los africanos hablan de "aventura" por mimesis o aprendizaje. Según esta hipótesis, así como los colonizadores - y, más tarde, los turistas hablaban abiertamente de sus aventuras, así también ellos tendrían derecho a irse a la aventura y conceptualizarla de forma parecida a la de aquéllos que los visitaban a ellos. Según esta hipótesis, en otras palabras, la aventura sería un producto de la modernidad. Habría nacido en Europa con la aventura de los exploradores primero y con la colonización tardía y el turismo más tarde y, en virtud de la inexorable modernización de las subjetividades colonizadas, se africanizaría más tarde.

Mi hipótesis es la opuesta a esta. No estoy de acuerdo con los lectores de Simmel en la asociación que establecen entre la aventura y la "modernidad". Ni siquiera creo que tal asociación esté presente en el ensayo original de Simmel. Las rupturas identitarias, la ausencia de pasado y de futuro, la extraterritorialidad y otros elementos de la aventura apuntados por nuestro autor estaban ya implícitos en viajes tan pre-modernos como el de Ulises a Troya y a Itaca o en los romances de caballerías medievales. Mi hipótesis es que tampoco en África la aventura es un fruto de la modernidad, aunque ésta pueda ser, supuesto, un caldo idóneo para su cultivo. Las culturas africanas conocen el movimiento desde tiempos inmemoriales. No sólo existen en el continente muchas culturas nómadas, sino que incluso aquéllas en apariencia sedentarias están dotadas de un nomadismo fronterizo que, al decir de algunos autores (KOPYTOFF, 1987, ILIFFE, 1995), ha sido fundamental para comprender la población del gran continente africano.

De todos modos no es mi objetivo el de describir la movilidad africana en general, sino de hablar de un movimiento en particular, denominado por la mayor parte de los analistas "emigración" y, por muchos que lo practican, "aventura". Y puesto que estamos hablando de una aventura en particular (la del viaje a Europa), quería comenzar por comprender Europa par le bas, desde el imaginario geográfico africano.

\section{Hacia una fenomenología de los lugares remotos}

¡Databo domboleeee! ¡Europea está leeeejos! (Frase con ideófono, oída a un campesino de la etnia baga de Guinea Conakry) 


\section{HUMANAS}

Uno de los componentes esenciales para que una experiencia subjetiva pueda ser catalogada de aventura, según Simmel, es su extra-territorialidad. La aventura sucede en otro lugar. Por supuesto que puede suceder en el lugar donde el sujeto vive, pero precisamente por vivir una aventura, el lugar adoptará otra cualidad. Creo que está noción de "otro lugar" es también esencial en la concepción africana de la aventura que estoy intentando resumir en este articulo.

Cuando vivía en Africa me di cuenta de que, para la mayoría de mis amigos y amigas, Europa era un lugar remoto, como ilustra la frase con que abrí esta sección. El concepto de "lugar remoto" lo tomo, con alguna modificación, de Edwin Ardener, quien escribió un inspirado (y, aun más importante, inspirador) articulo sobre las "areas remotas", lugares que existen en el imaginario antes de ser "empirizados" por los sentidos y convertidos en lugares concretos (ARDENER, 1987). Lugares como la Atlántida, las Antípodas, la "Isla Brasil" (más tarde empirizada en el país hoy denominado Brasil). Un lugar remoto no es un lugar lejano. Un lugar remoto es un lugar que está muy lejos. O, para expresarlo gráficamente, que está muuuuuy lejos. Es un lugar que no tiene continuidad con el lugar vivencial, con la Lebenswelt en que estamos instalados. Uno de los errores de la antropología ha sido suponer que la forma humana de vivir el espacio es claramente traducible de una cultura a otra, lo que ha conducido a errores tales como afirmar que los nuer viven en Nuerlandia o que los pueblos fulbé vienen de Egipto, en vez de explorar qué significa "nuerlandia" para los Nuer, o qué imágenes se evocan con la palabra "Egipto" en el imaginario de unos ganaderos que viven a miles de kilómetros del país denominado Egipto.

No quiero ser relativista y afirmar que a cada cultura le corresponde una forma de pensar el espacio, o de estar en él. De hecho, si en algo podemos basar el universalismo es precisamente en que todos los seres humanos tenemos unos esquemas orientativos comunes que nos permiten clasificar el mundo sensorial según la derecha y la izquierda, delante y atrás, arriba y abajo (podríamos añadir a los vivos y a los muertos para obtener la cuaternidad heideggeriana, pero precisamente de la universalidad de esta división tan clara entre vivos y muertos no estoy nada seguro). Pero de aquí a afirmar que todo pueblo piense el territorio de forma similar hay un gran salto. Tras varios años de investigación entre los bagas de Guinea, todavía no sé muy bien qué les está pasando por la cabeza cuando ellos hablan del Dabaka expresión que traducen al francés como le pays baga, pero que ni es un país ni me parece que ni siquiera sea un territorio en nuestra acepción del término. Tampoco sé, por supuesto, qué tienen en mientes cuando hablan de Databo, concepto que traducen como "Europa". Ciertamente, no lo mismo que yo. 
El esquematismo corporal va bien para entender el universalismo del espacio vivido por los sentidos, pero fuera de éste existen espacios que sólo el intelecto conoce, de los que no tenemos experiencia sensorial directa. Pongamos, como ejemplos, Portugal o Europa. No conocemos la espacialidad de Portugal o de Europa porque seamos portugueses o europeos, sino porque desde nuestros días escolares la tenemos grabada en nuestra memoria icónica y la imagen nos ayuda a situarnos en el mundo de una forma determinada: la forma portuguesa (o europea) de estar en el mundo. Pongamos ahora otro ejemplo: Etiopía. ¿Qué sabemos nosotros de Etiopía? ¿Conocemos su forma? ¿Con qué países tiene fronteras? ¿Tiene costa en el Océano Índico, en el Mar Rojo, en ambos, o en ninguno? Posiblemente pocos lectores (portugueses o europeos) serán capaces de responder inmediatamente a estas preguntas. Etiopía queda muy lejos de su experiencia inmediata. ¿Quiere esto decir, por lo tanto, que Etiopía es un lugar remoto? Rotundamente no. Todos sabemos que Etiopia, por poco clara que esté su imagen en nuestra mente, está en Africa, y la imagen de Africa la conservamos todos: es aquella especie de estalactita que empieza en Marruecos y que tiene un cuerno a la derecha en el que, me parece recordar, se sitúa el país del que hablamos. Si queremos saber más cosas sobre Etiopía vamos al Atlas que tenemos todos en casa (o, mucho mejor, al Google Earth $\left.{ }^{\circledR}\right)$ y en seguida tenemos los datos que nos hacen sentir ese país lejano de una forma continua y contigua a nuestra vivencia. Etiopía está lejos, pero no está remotamente lejos, no está realmente ailleurs. Lo que está remoto es aquello que ni siquiera sabríamos buscar en un mapa: Xanadú, la Atlántida, el Edén. U-topía.

Es un lugar común decir que conocer el mapa nos ha hecho desconocer los territorios. La geometría nos ha olvidado a olvidar, como no se cansó de repetirnos Husserl, que la tierra, en cuanto lugar vivenciado y no sólo pensado, es rotundamente plana. El mapa no es una representación primaria o directa, sino una herramienta para representarnos el espacio de una forma muy distinta a como en realidad lo percibimos, una herramienta de cuya complejidad no solemos ser conscientes. Yo me di cuenta de ello cuando regalé un atlas a unos chavales guineanos, de la comunidad baga en la que vivía, que me estaban siempre preguntando de donde salía (de miyiefe?). Ingenuamente, pensé que al regalarles un atlas y enseñarles el mapa de Africa y el mapa de la Península Ibérica podrían comprender mi origen en relación a donde estábamos. Sin embargo, todo aquello no les decía nada de nada. Lo que ellos querían saber era de dónde venia, y no en qué página podían encontrar un dibujo anaranjado en el que ponía Catalogne. "Vale, Ramon, este dibujo es tu país, pero tú, ¿de miyefe, de dónde sales?" me venían a preguntar.

Demasiado a menudo no nos damos cuenta de que los modos de pensar los espacios tienen unas historias culturales por atrás y suponemos, en virtud de un universalismo mal temperado que, si nosotros vamos a África, 
los africanos también deben poder venir a Europa. Pero nos olvidamos que para nosotros Africa está "allá abajo" (iporqué abajo y no arriba?) y en cambio Europa para los africanos está... no saben muy bien dónde, pero muuuuuy lejos.

Cuando comencé a hacer historia oral con los viejos bagas, me encontré a menudo con la afirmación, pronunciada por los ancianos, de que los bagas venían de Itchopi. Cuando les preguntaba dónde estaba Itchopi, no lo sabían. Itchopi era Itchopi: el lugar del que venían. De hecho, no entendían muy bien mi pregunta. ¿Qué significa "dónde"? Itchopi no está en ningún lugar, igual que el Dabaka ("país baga") no está en ningún lugar. El Dabaka es el mundo en el que vivimos: Itchopi el mundo del cual venimos. Algunos jóvenes escolarizados y, por lo tanto, más documentados, me decían que Itchopi era Etiopía o Egipto. O sea, querían concretizar el lugar remoto de Itchopi en el mapa de África: es esta mancha de color verde sobre la que se ha escrito la palabra "Etiopia". Pero precisamente Etiopia es uno de los conceptos topográficos mas problemáticos y polisémicos que haya conocido la humanidad: su referente no era el mismo en un texto homérico, en el Antiguo Testamento, en un texto portugués del segle XVII (en los que a veces lo que ahora es Guinea aparece como Aethiopia minor), en los textos de Marcus Garvey o en la música de Bob Marley. Durante miles de años, "Etiopía" ha sido un signifiant flottant, para agarrarme a la boya de Lévi-Strauss. Por lo tanto, decir que según la historia oral los bagas tienen un origen etiope (en el sentido "mapal" del término) sería un error historiográfico muy grave. La "historia oral" no nos dice que los bagas estuvieran en Etiopía. Ni siquiera nos dice, si la escuchamos atentamente, que así lo piensen: lo que dice es que los bagas sitúan su origen en un lugar remoto que de una manera o de otra han llegado a denominar Itchopi.

\section{Europa como lugar remoto}

Volvamos ahora a Europa. Europa (para los bagas Databo, que literalmente significa "el lugar de los blancos", de forma parecida a como Etiopía significaba para los griegos homéricos "el lugar de los negros") es también un topos cuya realidad geográfica es difícil de concretar. La historia nos dice en que muchas culturas no-occidentales identificaron Europa con un lugar mítico, o sea, en mi vocabulario, remoto. MacGaffey ha explorado el significado de Europa y de Occidente en general desde la óptica de los pueblos del Congo, mostrando como, en la cosmología centroafricana, el lugar de donde llegaban los invasores blancos se fundía con el lugar al que iban los africanos muertos (MacGAFFEY, 1972). Evidentemente, sin considerar que Europa fue para otros pueblos un lugar remoto, no entenderíamos los famosos cultos cargo de Polinesia y Melanesia ni por qué, según muchas culturas, los blancos vienen del mundo de los muertos, o de un mundo en el cual los muertos se confunden con los vivos. 
En muchas culturas religiosas africanas, hay una fusión topográfica entre el mundo de los blancos y el mundo invisible donde viven genios, espíritus y brujos, un mundo que, a menudo, es también el mundo de los sueños. Entre los bulongic, un subgrupo de los bagas estudiado por mi amigo David Berliner, el mundo invisible se denomina "París". Los brujos vienen de París, los genios viven en París, los niños, cuando nacen, vienen de París. Esta ultima afirmación no nos sorprende demasiado, toda vez que también para muchos ibéricos, probablemente porque París fue durante mucho tiempo una ciudad ideal, casi mítica, sitúan a París como el centro del que llegaban los niños traídos en cigüeña.

Los bulongic más documentados, según me explica David Berliner, afirman que el París invisible y el París ciudad son dos París distintos: una cosa es el mundo invisible de los brujos y de los espíritus (los bagas sitem, el subgrupo con quien viví yo, lo denominan dabal) y otra cosa es el Paris capital de Francia. Pero seguramente para mucha gente los dos París se funden en un único lugar remoto: Paris, horizonte en el que la fantasía y la realidad se funden (tal vez para muchos ibéricos de generaciones anteriores a la mía París era más un lugar remoto que una ciudad concreta, una ciudad de aventura, más que un espacio de vida cotidiana).

Cuando oímos hablar de Europa en contextos no occidentales, tenemos que tener en cuenta que también Europa puede haber sido un lugar remoto, y que para muchos continúa a serlo. Kimi me asegura que cuando el vivía en su aldea mandinga en Guinea Bissau en la década de los 70s y 80s, oían los relatos de los aventureros que habían ido a Europa como si volvieran de otro mundo, y que muchos creían que el frío con que era descrito el paisaje europeo era de hecho el agradable fresco celestial que, según el imaginario mandé musulmán, caracterizaba el estado de gloria que debía seguir a la tórrida vida terrenal. Muchos aventureros, me asegura mi amigo, preparaban su ida a Europa convencidos de que viajaban al mismísimo mundo de la gloria...

Una característica de la historia cultural de la humanidad es la conversión de lugares remotos en lugares geográficos concretos, de aquellos que están más arriba o más abajo, más a la izquierda o más a la derecha de nosotros. Lugares como Brasil, Guinea, o Etiopía fueron remotos y tienen ahora una geografía concreta. Hay lugares que continúan a ser remotos (el Avalon de la leyenda artúrica, el Manding de la épica mandé, la Atlántida de los textos platónicos) y hay quien se devana los sesos para situarlos en el mapa (hay quienes intentan situar el Paraíso en la geografía real). Talvez una característica de los aventureros sea, precisamente, su tenacidad y, de facto, capacidad para establecer la realidad concreta de muchos lugares remotos. En este sentido, los aventureros, como los tricksters de muchos mitos, son elementos mediadores que conectan mundos incomunicados. Algunos, al volver y explicar sus viajes, desmitifican los lugares remotos y ayudan a transformarlos en lugares mapables. 
Sería el caso del aventurero tipo Ibn Battuta. Otros, en cambio, presentan los lugares remotos como fantasiosos y ayudan a mantenerlos en la distancia, afirmando que los lugares remotos son accesibles, mas sólo tras muchas dificultades, penurias y riesgos. Es el aventurero tipo Marco Polo. A este tipo pertenece aquellos que, como los viajantes que escuchaba mi amigo guineano cuando era pequeño en su aldea mandinga de Guinea Bissau, afirmaban haber estado en la mismísima gloria, alimentando los sueños de que se nutre la imaginación de los jóvenes que los oyen, de los futuros aventureros.

\section{Centrípetos y centrífugos: el aventurero como héroe}

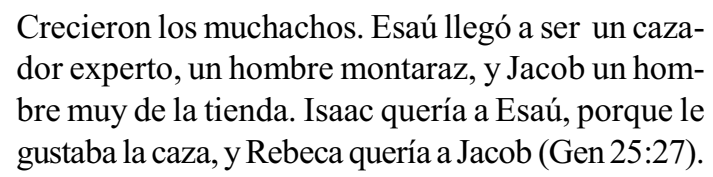

Hace apenas unas semanas me encontré a Toy, un angoleño que suele pasar el día en un parque situado al lado de mi casa, en el centro de Lisboa. No era la primera vez que lo veía; se trata de un muchacho muy amable a quien me encuentro a menudo y con quien varias veces he entablado conversa. En una ocasión anterior me explicó que emigró a Europa para jugar al fútbol, pero las cosas corrieron mal, no tuvo suerte con el fútbol y terminó en las drogas. Lo rescató de la droga una asociación evangelista. Hoy ha dejado las drogas, pero está bastante alcoholizado. A pesar de lo dura que es su vida, encuentra tiempo para trabajar de voluntario en una organización caritativa de unas monjas, ocupándose de repartir ropa y regalos entre personas menos afortunadas que él y que no tienen ni un lugar donde dormir. En la charla del otro día, el joven se expresó sobre su vida en Angola y sobre su madre con un tono de tristeza tan grave que me hizo sospechar que se arrepiente de haber iniciado el trayecto migratorio, aunque no me atreví a preguntárselo. Me limité a preguntarle por qué lo había iniciado. Me explicó que vino porque tenía ganas de irse de Angola, de ver mundo y de convertirse en un gran jugador de fútbol, puesto que, al parecer, era una joven promesa en Luanda. "Vamos, que tenías ganas de aventura" le resumí. El me miró atónito, riendo: "sí, eso es, de aventura; es así como decimos en Angola, ¿cómo lo sabe?"

Lo sabía, claro, porque aparte de hablar con él llevo tiempo hablando con africanos, y el concepto surge en nuestras conversaciones en innumeras ocasiones, tanto en las establecidas en Africa como en Europa. Tengo que añadir que no siempre aparece de forma positiva. Mientras que Toy y otros angoleños (como el mencionado Vicente, amigo suyo) ven la aventura como algo positivo (aunque pueda salir mal), algo a lo que se atribuyen un derecho inalienable, en otros casos, en cambio, aparece de forma negativa. Así, en las misas kimbanguistas que últimamente estoy acompañando con bastante frecuencia, el pastor, 
también angoleño, utiliza mucho el concepto de aventura para amonestar a sus feligreses. "Esto no es una aventura", ha dicho en varios de sus sermones, para recordar que a la gente que ir al culto es algo muy serio que debe formar parte de sus vidas. Parece como si el pastor hubiera leído a Simmel y supiera que por aventura hay que entender un fragmento vital extra-temporal y extra-territorial, un alter ego que vestimos y que luego nos quitamos como quien se pone y se quita una máscara. No es el caso del culto religioso. Éste tiene que ser algo serio, que forme parte integral, y hasta fundacional, de nuestras vidas.

Pero, insisto, no es sólo en Europa donde los africanos hablan de aventura. El aventurero es una forma social bastante consensuada en Africa subsahariana. Semejante afirmación puede sorprendernos un poco, porque tenemos la impresión de que la aventura es una noción muy occidental e incluso muy "moderna": el individuo que abandona su hogar, enfrentándose al mundo "solo ante el peligro", según reza la castiza expresión. Pero en África, y creo que con independencia a si hablamos del Africa "moderna" o de la "tradicional", también se habla mucho de aventura y en muchas lenguas, como vimos al inicio de este trabajo, hay conceptos que se traducen directamente por aventura o aventurero, utilizados para referirse a un tipo de personaje bastante estereotipado: el que se va más allá de los limites de la comunidad, aquél que quiere "conocer mundo". Como reza un refrán de los luvale, grupo étnico de Angola y Zambia: "Sólo el que viaja ve el elefante" (citado en SILVA, 2004; 56). ${ }^{2}$

En todas partes se acepta que hay personas que sienten la necesidad de irse y otras a quienes les gustar más quedarse en casa. Es una dualidad que el imaginario occidental conoce bien y a la que se ha recorrido abundantemente. Mi ejemplo preferido es el de la novela Les Météores de Michel Tournier (1975) sobre unos gemelos que viven una atracción opuesta hacia el nomadismo y el sedentarismo. Mientras que uno siempre desea irse de donde está ( $\sin$ saber muy bien por qué) e irse a conocer mundo y a ver elefantes, el otro está plenamente integrado en la dualidad que los dos forman y desearía que su hermano no fuera tan curioso. Como es habitual en el novelista francés, en esta novela Tournier está reelaborando una temática bíblica. Sus personajes, los gemelos Jean y Paul, son un avatar del par Esaú y Jacob (a su vez un avatar de Caín y Abel, si bien estos no eran gemelos) con quienes hemos abierto este apartado. Los hermanos Esaú y Jacob, centrífugo y centrípeto respectivamente, tienen una relación con el espacio diametralmente opuesta. Para Esaú, el primero en nacer, el espacio es algo que tiene que ser conquistado: es la acción humana la que crea el espacio.

\footnotetext{
${ }^{2}$ El refrán es de hecho una abreviación de uno más largo "Sólo el que viaja ve el elefante; los ancianos no" (SILVA, 2004; 56). Simmel se sentiría reconfortado con este refrán. Según él, en efecto, la aventura es cosa de jóvenes. Los mayores tienen una relación con la vida demasiado centrípeta, pueden tener accidentes periféricos, pero no tienen el afán que tienen los jóvenes por imponer su elan vitan. Se contentan con controlar el centro más que por expandir los límites.
} 
Para el segundo, preferido por la madre, el espacio existe de forma no problemática, como matriz de existencia y de actividad familiar. Como sabemos bien, en virtud de una traición al ciego Isaac (orquestada por su esposa Rebeca) será el hermano más joven, Jacob, quien se llevará la bendición del padre y se convertirá en el heredero del linaje, cambiando así el futuro de la historia de una gran parte de la humanidad.

Hurgando en el imaginario africano (tan similar al imaginario bíblico y al occidental) también encontraríamos parejas míticas similares (ya hemos mencionado los gemelos avunculares del protagonista de l'enfant noir de Camara Laye) y también ejemplos de hermanos menores que se convierten en herederos por encima de los primigenios: es de hecho un esquema muy recurrente, como nos explica precisamente Camara Laye al hablarnos de sus tíos ${ }^{3}$. Pero, sobre todo, encontraríamos la idea, común a toda la humanidad, de que hay gente que queda y gente que se va. La dicotomía no tiene por qué estar acompañada de ninguna valoración ética. El querer irse no está mal visto ni infravalorado, aunque la valoración cabal de cada caso de aventurero dependerá mucho del porqué de la partida. A veces, es cierto, el aventurero se va porque se lo expulsa (directa o indirectamente) o porque es socialmente excluido. Muchas veces, sin embargo, su partida es voluntaria y tan inexplicable como la del personaje de Tournier. Para continuar con el imaginario luvale, parece como si haya individuos a los que, cuando se les dice que en lugares distantes hay elefantes, les entran unas ganas irresistibles de ir a verlos con sus propios ojos. En cualquiera de los dos casos, el hecho de marcharse lo excluye y, cuando el aventurero quiera volver tendrá grandes dificultades en re-integrarse. De mi estancia entre los bagas de Guinea recuerdo dos casos de aventureros que se fueron de sus pueblos (uno de ellos a Senegal, el otro a Gambia: no siempre la aventura es una migración transcontinental ni mucho menos). Cuando finalmente decidieron volver a su tierra nativa tuvieron muchas dificultades, porque ser baga es ser labrador, y el labrador se hace labrando, no viajando. Tras varios meses de estancia infructuosa y marginal ambos terminaron por marcharse a vivir a los suburbios de una ciudad próxima a sus aldeas (que continúan a visitar con asiduidad), donde hasta hoy sobreviven con trabajos muy precarios y experimentando una doble exclusión social: ni son propiamente habitantes de la ciudad, ni son labradores bagas. $\mathrm{Su}$ aventura, como la de Cheick Hamidu Kane, como tantas otras, ha sido claramente ambigua.

\footnotetext{
"En nuestro país, se considera primogénito al primero de los gemelos en nacer. Puede acontecer, sin embargo, que este derecho de primogenitura sufra alguna alteración, porque siempre hay uno de los gemelos que se impone más especialmente y que, aunque no sea el primero en nacer, se autodenomina heredero" (LAYE, 1953; p. 38). El tema del "hermano menor" en el pensamiento mandé ha sido abundantemente explorado por los especialistas. Véase la colección de textos sobre el tema dirigida por Jan Jensen y C. Zobel (1996).
} 
La gente que se queda, normalmente, no tienen demasiados conocimientos sobre la vida de los aventureros. Muchas veces, cuando estaba en Guinea, me encontraba con padres y madres que me decían: "mi hijo está en Europa". "Ah", respondía yo, "¿qué hace allí?". "La aventura", era todo cuanto sabían decirme. Pero siempre estaba claro que saber sólo la aventura era mala señal. Lo que les gustaría era oír sus hazañas, tener información. Una línea de investigación que tiene que ser profundizada es precisamente la de los canales por los cuales la información sobre la aventura de alguien llega a los oídos de su público. No hay que centrar la atención exclusivamente en los aventureros. Este tiene que ser comprendido en relación con las expectativas y vivencias de aquellos que deja atrás. Hay un aspecto digamos heroico en todo aventurero. Esto no significa que todo aventurero sea un héroe. Pero talvez sí que todo héroe sea un aventurero y que el modelo de acción heroica esté presente en la forma de pensar la acción aventurera. El héroe, tal como aparece en la épica mandé, por ejemplo, es un individuo (normalmente varón y normalmente joven) que se fue más allá de los límites de su comunidad, resolvió un problema, creó una aldea, mató un dragón, introdujo una tecnología, construyó un puente, cruzó un río, fue al mundo de los muertos, etc. Cualquiera que haya sido su hazaña, el héroe es hoy inmortal, vive en la palabra del griot, en los estribillos de las canciones, en los juegos de los niños, en la fantasía de los jóvenes. Se jugó la vida, y hoy es famoso.

Según Charles Bird y Martha Kendall, autores de un texto fundacional para estudiar la épica mandé (BIRD \& KENDALL, 1980), el héroe es un individuo "centrífugo", que huye de la centripetalidad del hogar. La centrifugalidad heroica, según estos autores, es generada en el conjunto de valores que los pueblos mandé denominan fadenya, el dominio del padre, mientras que la centripetalidad se transmite por el badenya, o dominio de la madre. La mayor parte de los hombres viven en un equilibro inestable entre el éxito individualizador a que los alienta el padre y el éxito comunitario y anónimo transmitido por la madre. Esta dicotomía está bien presente también en la novela de L'enfant noir de Camara Laye ya referida, una novela que debe mucho al imaginario épico mandé. La mayor parte de los hombres (más que de las mujeres, cuyas tensiones son otras) viven en un equilibrio inestable entre el éxito individualizador a que los anima su padre ("se un buen cazador, el mejor músico, el mejor orador, se famoso, haz que tu nombre se oiga y se repita") y el éxito comunitario, anónimo transmitido por la madre ("piensa en tus hermanos, en tu esposa, en tus hijos, en tus campos"). El héroe clásico mandé (un Sundiata Keita, para citar al más conocido) rompe el equilibrio, tiene una excelencia en el dominio del fadenya, pero - paso de gran importancia - transforma su éxito individual en un éxito colectivo. 


\section{HUMANAS}

Está tensión entre la centripetalidad y la centrifugalidad se da no sólo entre los pueblos mandé, sino entre muchos pueblos africanos, y creo que sirve no sólo para explicar el heroísmo clásico de los mandé, sino también para percibir el equilibrio, a menudo inestable, con el que los africanos navegan el barco de su personalidad contra dos fuerzas opuestas: un viento huracanado que se los lleva hacia el éxito individual y una mala mar que amenaza con sumergirlos en el anonimato de la vida comunitaria. En un artículo anterior exploré esta dicotomía en la noción de persona de los bagas (SARRÓ, 2005), pero sin duda la encontraríamos también en muchos otros pueblos africanos.

\section{Éxitos y fracasos}

El heroísmo, decíamos, es un modelo (que no el único) con que a menudo se piensa la acción aventura. Cuando hablo con africanos me encuentro con esta idea tan exigente: "Yo no puedo volver: sería un fracaso" me dicen algunos. "Yo sólo volveré cuando haya tenido éxito" me dicen otros. "Esta sí que ha tenido éxito" - me decía un día mi amigo Fara en el bar del aeropuerto de Conakry, señalándome una mujer bastante famosa en aquella ciudad - "se pasa la vida haciendo aller-retour entre Conakry y Europa". He aquí algo a tener en cuenta cuando hablamos de/con inmigrantes africanos en Europa: mientras que aquí son individuos prácticamente invisibles, para uno de ellos hay un montón de personas en algún lugar, tal vez remoto para nosotros, que esperan su retorno heroico - o por lo menos oír hablar de su fama.

La presión del éxito es un componente muy importante para comprender a los emigrantes y las presiones psicológicas y sociales que pesan sobre ellos. Un ejemplo trágico aparece en la novela de Fatou Diome Le ventre de l'Atlantique (2003) más un documental sobre el Africa de hoy que un romance. En un episodio suelto de esta novela se cuenta la vida de un joven que fue a Europa. Al igual que Toy, mi vecino angoleño, el joven senegalés de la novela de Diome emigró para jugar a fútbol pero, también al igual que Toy, tuvo mala suerte, su aventura corrió mal y terminó en la calle. Finalmente fue detenido de forma meramente rutinaria por la policía francesa que, al comprobar que no tenía ningún papel en regla, lo repatrió a Senegal. El chico llegó totalmente humillado, pero su humillación no fue nada comparada con lo que le esperaba en su aldea de la costa. En el pueblo natal habían ya llegado rumores de que el chico estaba a punto de llegar. Se había incluso preparado una gran fiesta para recibir al aventurero en retorno. Se esperaba que narrara sus aventuras, que repartiera sus riquezas, que colaborara para que su fama individual se convirtiera en la fama colectiva, como era de esperar de todo héroe que se prestara. El chico vivió mal la tensión y empezó a caer en una profunda depresión. Finalmente se descubrió que su periplo europeo había sido un fracaso total. 
Abandonaron al muchacho a su mala suerte, fue socialmente excluido, y terminó por suicidarse, arrojándose al Océano Atlántico, monstruo que en su día lo fascinó y que terminó por devorarlo.

Desgraciadamente, el ejemplo del suicida no sirvió para nada. Para el resto de chicos de la aldea, totalmente fascinados por Francia y por lo occidental, el pobre muchacho había tenido mala suerte porque no supo jugar bien sus cartas. Pero a ellos les iría mejor. Ellos sí que tendrán éxito. Un buen aventurero no se deja amedrentar por los relatos de fracaso de aventureros anteriores. El aventurero, como bien supo Simmel, no conoce el pasado. Mi amigo Kimi Djabaté me lo explicaba el otro día. Cuando él viaja a su aldea en Guinea Bissau intenta convencer a los parientes más jóvenes para que tengan juicio, de que no vale la pena emigrar a cualquier coste, de que la vida en Europa es muy dura, porque falta el trabajo y sobra el racismo. Pero entonces lo acusan de querer frustrar sus sueños y, más aún, de egoísmo, de querer quedarse para él solo los beneficios de la vida aventurera. Pero si el emigró y tuvo suerte, e incluso éxito, ¿por qué no pueden emigrar ellos? En su última visita a Guinea Bissau hace un año y medio, Kimi intentó disuadir a un pariente de su aldea particularmente tenaz en su intención aventurera. No hubo manera. Cuando Kimi ya se había vuelto para Portugal, su pariente lió el atillo y se fue al Senegal. Desde allí se alistó para embarcar en un cayuco hacia Canarias. En él perdió la vida. Como a tantos otros, el voraz Océano se lo tragó, a él y a sus sueños de aventura.

\section{El telar de Penélope: la aventura y la cultura femenina}

En el apartado anterior recordaba las palabras de Fara en el aeropuerto de Conakry, sentados al lado de una mujer cuyo éxito mi amigo exaltaba. Esto puede responder, afirmativamente, la pregunta que muchos lectores y, sobre todo, lectoras tienen en su cabeza a esta altura del artículo. ¿Existen aventureras? ¿O estamos hablando puramente de un modelo de acción puramente masculino?

De una lectura atenta de Simmel, queda claro que, para él, la aventura es una acción masculina. De una conversación atenta con los africanos, queda claro que los aventureros son los hombres. Ninguno de mis amigos africanos, en efecto, diría que una mujer sea "aventurera" porque afirmarlo sería poner en cuestión la integridad ética de la mujer. Como para Simmel, también para ellos el concepto de aventura tiene armónicos eróticos y sexuales. Esto no significa, sin embargo, que ninguno de ellos piense que las mujeres no emigren. Las mujeres africanas emigran, y mucho, pero su acción se conceptualiza de forma distinta a la de los hombres. Podemos recurrir, una vez más, a Simmel. Simmel señala en su ensayo que el aventurero mantiene una relación "no orgánica" con el mundo, estructuralmente opuesta al "trabajador", que mantiene una relación orgánica con su entorno. Simmel no elabora este punto, 
pero curiosamente cobra especial sentido al pensarlo en relación con la emigración femenina africana. Porque, evidentemente, no podemos decir que la aventura sea exactamente el trabajo de una mujer, a no ser que estemos pensando en el tipo de trabajo más indigno para ella. En la medida de lo posible, las mujeres emigran para ejercer trabajos que las dignifiquen $y$, en concreto (como queda claro en el recién citado éxito de la mujer de Conakry), en trabajar en redes de comercio, en lo que en el África francófona se denomina aller-retour (viajes de ida y vuelta para comprar cosas al por mayor en Europa y revenderlas en Guinea). Es ahí donde suelen realizar su éxito.

La movilidad de las mujeres en África, y su papel en tejer redes de comercio y de parentesco transnacionales, ha sido abundantemente estudiada. En África occidental, trabajos como los de Philip Havik sobre las mujeres lusoafricanas (2004), los de Marzia Grassi sobre las comerciantes caboverdianas (2003), los de Marianne Ferme (2001) o Rosalind Show (2002) sobre la fragilidad estructural de las esposas (a menudo procedentes de otras aldeas o etnias) en las sociedades de Sierra Leone, los trabajos de Marina P. Temudo (en prensa) ilustrando la enorme libertad que poseen las balantas casadas en sus viajes, en los que se acepta incluso que tengan relaciones extra-conyugales ("aventuras", uno se siente tentado a decir); todos estos son bellos ejemplos de la diversidad de patterns de movilidad femenina. No creo, sin embargo, que en ninguno de estos autores encontremos referencias explícitas a la "aventura". Cuando hablamos de "aventureros" en África estamos hablando (como cuando hablamos de héroes), de varones, y en especial de varones jóvenes. La aventura es hoy, como lo fueron antaño las iniciaciones, una forma de construir, o de reconstruir, modelos (ahora transnacionales) de masculinidad africana.

Simmel fue precisamente perspicaz en su aproximación al dominio femenino, siempre insistiendo que los aspectos subjetivos de feminidad tienen que ser estudiados de forma independiente a los de la masculinidad. Tal vez la noción central de su texto "cultura femenina" (SIMMEL, 1911b), esto es, que las mujeres son holísticas y los hombres particularistas, se aplique a los modelos de movilidad africana. Según esta visión simmeliana, recordémoslo, la mujer percibe la realidad como un todo y es capaz (como sabemos bien y envidiamos aún mejor todos los hombres) de hacer varias cosas a la vez, porque está manipulando el todo, no las partes. El hombre, en cambio, tiene que concentrarse en la parte: o hace esto o hace aquello, pero no las dos cosas a la vez. Tal vez la mejor metáfora sea la del aventurero Ulises y su esposa Penélope. Mientras que Ulises vive aventura tras aventura (pero nunca más de una simultáneamente) Penélope teje y desteje un sudario al mismo tiempo que lidia con sus pretendientes y trata del hogar. No es tanto su pluralidad de acciones lo que me interesa resaltar con el hecho de que el tejer aparece en muchos mitos humanos como símbolo del holismo, de la ligazón de las cosas. 
Especial atención merece que es precisamente el sudario de Laertes, padre de Ulises, lo que está tejiendo y destejiendo, prometiendo a sus pretendientes que, una vez lo tenga acabado, se casará con alguno. Parece como si de su actividad tejedora dependiera no sólo su propia vida y temporalidad, sino también la de los Laertíadas. He aquí resumida una doble actividad que también encontramos en la feminidad genésica africana: tejer redes comunitarias y temporalidades humanas. De ellas dependen no solo la procreación de su grupo, sino también (y, a veces, sobre todo) la del de su marido. A diferencia del modelo homérico, en el modelo africano las mujeres africanas no expresan esta "cultura femenina" quedándose en casa, sino también viajando, si bien este viaje, a diferencia del masculino, no se conceptualice bajo el modelo de aventura o de heroísmo (aunque sí de éxito). El viaje femenino y el éxito de las mujeres avanzan por otros derroteros. Serán, espero, objeto de futuros apuntes simmelianos sobre la emigración y la movilidad humanas.

\section{Referências bibliográficas}

ARDENER, E. On remote areas: some theoretical considerations. In: A. Jackson (Org.), Anthropology at home (ASA Monograph 25). Londres: Tavistock, 1987.

BIRD, C.S. \&KENDALL, M.B. The Mande hero: text and context. In: I. Karp \& C.S. Bird (Orgs.). Explorations in African systems of though. Pp. 13-26. Bloomington: Indiana University Press, 1980.

BORDONARO, L.I. Living at the margins: youth and modernity in Bijagó (Guinea Bissau). Tesis doctoral en antropología, ISCTE (Lisboa), 2006.

DIOME, F. Le ventre de l'atlantique. Paris: Ed. Anne Carrière, 2003.

FERME, M. The Underneath of things: violence,history, and the everyday in Sierra Leone. Berkeley, Los Angeles y Londres: The University of California Press, 2001.

GRASSI, M. Rabidantes: comércio espontâneo transnacional em Cabo Verde. Lisboa: Imprensa de Ciências Sociais, 2003.

HAVIK, P.J. Silences and soundbytes: the gendered dynamics of trade and brokerage in the pre-colonial Guinea Bissau region. Münster: Lit Verlag, 2004.

ILIFFE, J. Africans: the history of a continent. Cambridge: Cambridge University Press, 1995. 
JENSEN, J. \& ZOBEL, C. (Orgs.). The younger brother in Mande: kinship and politics in West Africa. Leiden: Research School, Centre for Non-Western Studies, 1996.

KANE, C.H. L'aventure ambiguë. Paris: Juillard, 1961.

KOPYTOFF, I. The internal African frontier: the making of African political culture. In: I. Kopytoff (Org.) The African frontier: the reproduction of traditional African societies. Bloomington y Indianapolis: Indiana University Press, 1987.

LAYE, C. (o CAMARA, L.). L'enfant noir. Paris: Plon, 1953.

LÉVI-STRAUSS, C. Tristes Tropiques. Paris: Plon, 1955.

MacGRAFFEY, W. The West in Congolese experience. In: P.D. Curtin (Org.). Africa and the West: intellectual responses to European culture. Madison: University of Wisconsin Press, 1972.

MAFFESOLI, M. Sociologie de l'aventure. In: Du nomadisme: vagabondages initiatiques. Paris: Les Livres de Poche, 1997.

SARRÓ, R. The throat and the belly: Baga notions of morality and personhood. Journal of the Anthropological Society of Oxford: 31(2): 167-84, 2005.

SARRÓ, R. Órganos vitales y metáforas mortales: un relato sobre hospitales portugueses y diáspora africana. Revista de Antropología Social (Madrid), 16 (en prensa), 2007.

SHAW, R. Memories of the slave trade: ritual and the historical imagination in Sierra Leone. Chicago y Londres: The University of Chicago Press, 2002.

SILVA, S. Vidas em jogo: cestas de adivinhação e refugiados angolanos na Zâmbia. Lisboa: Imprensa de Ciências Sociais, 2004.

SIMMEL, G. La aventura. In: Cultura femenina y otros ensayos. Madrid: Revista de Occidente: 123-38, 1911a [1936].

SIMMEL, G. Cultura femenina. In: Cultura femenina y otros ensayos. Madrid: Revista de Occidente: 13-56, 1911b [1936].

TEMUDO, M.P. Fyere Yam: Guinea Bissau's Balanta from "deep rural" to presidential palace. African Studies Review (en prensa).

VIVANCO, L.A. \& GORDON, R.J. (Orgs.). Tarzan was an Eco-Tourist...: and other tales in the Anthropology of adventure. Nueva York y Oxford: Berghahn Books, 2006. 
La aventura como categoría cultural: apuntes simmelianos sobre la emigración subsahariana Ramon Sarró

YENGOVAN, A.A. Simmel and Frazer: the adventure and the adventurer. In: L.A. Vivanco y R.J. Gordon (Orgs.). Tarzan was an eco-tourist...: and other tales in the Anthropology of adventure. Pp. 27-42. Nueva York y Oxford: Berghahn Books, 2006.

WARDLE, H. Jamaican adventures: Simmel, subjectivity and extraterritoriality in the Caribbean. Journal of the Royal Anthropological Institute (N.S.), 5(4): 523-39, 1999. 